Article

\title{
Toward a Smart Sustainable Development of Port Cities/Areas: The Role of the "Historic Urban Landscape" Approach
}

\section{Luigi Fusco Girard}

Department of Architecture, University of Naples “Federico II”, Via Toledo 402, Naples 80132, Italy; E-Mail: girard@unina.it; Tel.: +39-081-253-8847/6; Fax: +39-081-25-38649

Received: 30 August 2013 / Accepted: 24 September 2013 / Published: 2 October 2013

\begin{abstract}
After the 2008 crisis, smart sustainable development of port areas/cities should be developed on the basis of specific principles: the synergy principle (between different actors/systems, in particular the socio-cultural and economic system), the creativity principle and the circularization principle. The Historic Urban landscape (HUL) approach becomes the guarantee that the transition toward the smart city development model is based on specific local cultural resources, and not only on technological innovations. In other words, the eco-town/eco-city strategy becomes culture-led. It stimulates places as spatial "loci" for implementing synergies and circularization processes. Without new evaluation tools and a widespread "evaluation culture” the risks in implementing HUL are very high.
\end{abstract}

Keywords: circularization processes; synergistic approach; smart city development; evaluation tools; cultural city base

\section{Introduction}

In the past few decades, sustainable development was first of all based on managing economic growth/prosperity, and sharing benefits also in a co-evolutionary perspective with the ecosystem. Since the 2008 economic/financial crisis, the challenge of sustainable development has first of all been about regenerating economic wealth, which has not yet been achieved, through new circuits of value creation [1].

Cities need to invest in improving their efficient organization in order to increase wealth production towards a sustainable development. Creativity and innovation do not only concern research and cultural industries, but also a city's organizational structure, which has to become less dissipative.

New unconventional forms of value creation and production are based on circular processes. The smart city image should be linked first of all to technologies able to produce a less dissipative and 
more efficient city organization. Circularization and synergies are the general principles for smart city sustainable development [2].

Port cities and port areas have a particular development potential. They may take on a key role in launching a smart sustainable development model, starting from local cultural resources for the activation of the creative processes of a circular economy through a synergistic approach, combining the port's economic, logistic and industrial activities with a cultural heritage regeneration, with the creativity of inhabitants. Port cities are key places where economic strength, competitiveness, human capital and global appeal, population and migration processes are increasingly concentrated. They are laboratories of creativity, stimulated by their specific cultural historic landscapes. Often the [3] ancient city boundaries coincide with the harbor area with its old warehouses, silos, wharfs, industrial archaeology, lighthouses and so on; sometimes this landscape is recognized as a UNESCO world heritage site.

Some good practices of a city's economic regeneration process are related to cultural heritage revitalization/recreation as a key local development resource. In many countries, some good practices of symbiosis starting from the industrial age already exist. The reconstruction [3] of interdependences between city and its port area means the integration of the industrial symbiosis model with its heritage/culture economic development model, and with the social economic system. An integrated perspective is then needed.

The thesis of this paper is that smart sustainable development of port areas/cities should be shaped on the basis of three principles for the regeneration of city wealth: the synergy principle (between different actors/institutions and systems like the socio-cultural and economic system etc.) [4], the circularization principle [5] (re-use, recycle, regenerate, in analogy to a natural system organization), and the creativity principle (introducing novel changes). This thesis corresponds to the old proposal of Patrick Geddes (1915) to interpret the city as an organism in evolution/transition [6]. A city, like any other organism, evolves/changes over time, adapting itself to satisfy human needs.

A city, as a dynamic complex system, is characterized by: interdependences (between human-made, natural, social capital, etc.); circular processes (which stimulate creativity) and synergies (which increase the resilience capacity).

Cultural heritage is a key component of the city system: it should be viewed as a dynamic adaptive subsystem that evolves over time (with changes) under the pressure of many different forces (due to economic growth, market pressures, decline, and regeneration processes), while still maintaining its identity, integrity and continuity. Assuming Geddes' interpretation, cultural heritage conservation and management should be characterized by a dynamic perspective, characterized by synergies, circular processes and creativity.

Against this background, the Historic Urban Landscape (HUL) [7] becomes a useful approach for leveraging city development while conserving "places"; for managing changes in activating circular processes and synergies (between city actors, points of view, different types of specialized knowledge, etc.). Circular processes promote resilience and synergies and stimulate creativity and thus sustainability. HUL can stimulate the implementation of "smart" city development, by integrating its scope (often limited only to technological innovations).

New tools, methods and approaches for planning and managing complex and dynamic urban systems are required to foster the creativity, resilience and sustainability of the city (reducing the 
conflict between specific interests and general ones). In particular, new tools are required to improve city governance. They can be based on pilot experiments, which are to be assessed so as to learn how to improve choices and promote the strategies of a circular economy (through reusing, recycling and regenerating materials, producing and using renewable energies and jointly regenerating the cultural heritage/landscape of cities). "Smart" development is based on innovations in city organization, on innovative technologies and also on a strong city cultural basis.

In the following sections, a more effective city model is proposed (Section 3 ) for the regeneration of the city wealth (Sections 5 and 6), stressing the role of specific approaches and evaluation tools (Sections 7 and 8).

\section{Port Cities and Port Area Characteristics}

The literature about port cities and port areas is rich. Many scholars coming from multiple specialized disciplines have examined in the past few years the dynamics of port cities, exploring in their essays similarities and dissimilarities. Hein [8] has recently gathered many studies on this topic (from Shubert 2011 to Ward, to Hayuth 1982, etc.) [8-11]. We will offer a concise overview here.

\subsection{Port Cities}

Port cities are core places: they lead the way in terms of economic strength [12]. For example, 14 out of the 20 economically strongest cities in the world are port cities. They are also the most competitive places (see Figures 1 and 2); 36 of the 50 most competitive cities are port cities.

Figure 1. Cities' economic strength (based on nominal GPD, GDP per capita, real GDP growth rate, regional market integration, households with annual consumption > 14,000 USD).

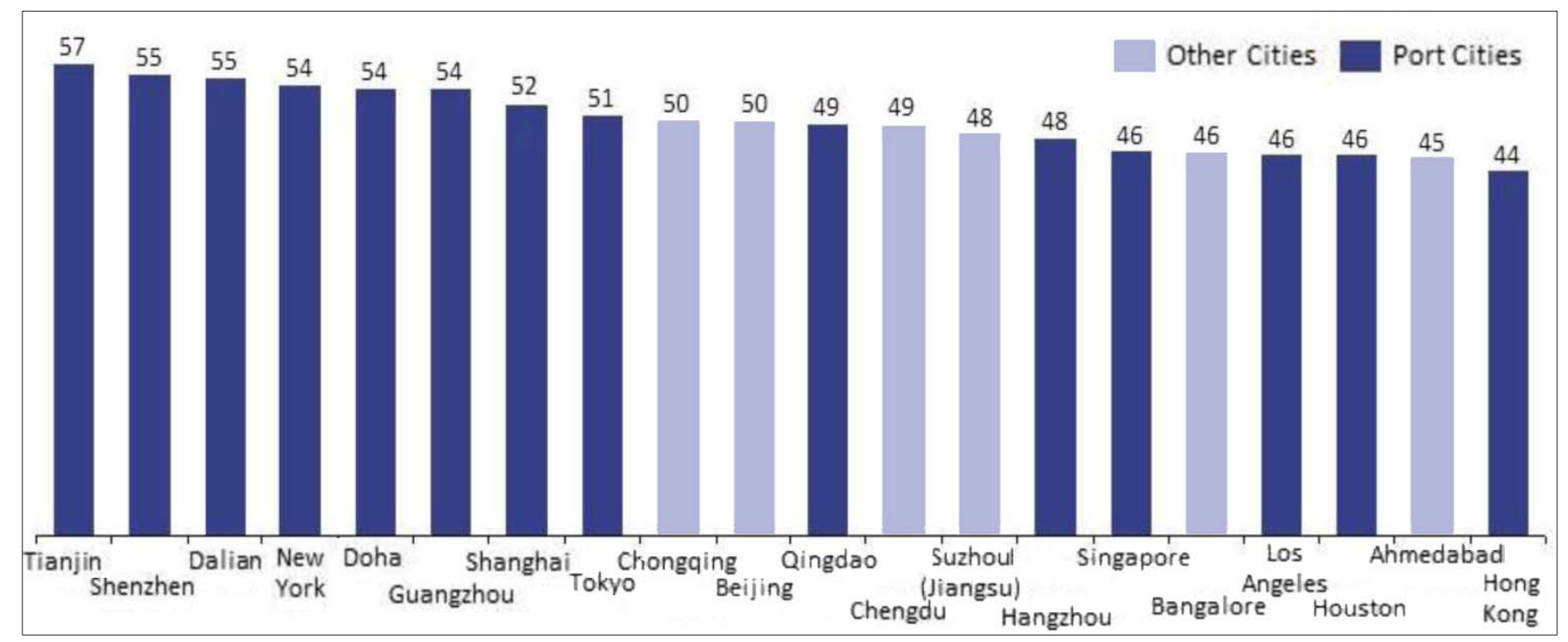

Source: The Economist_Economist Intelligence Unit (2012) [12]. 
Figure 2. Cities' competitiveness rank (economic strength, physical capital, financial maturity, institutional effectiveness, etc.).

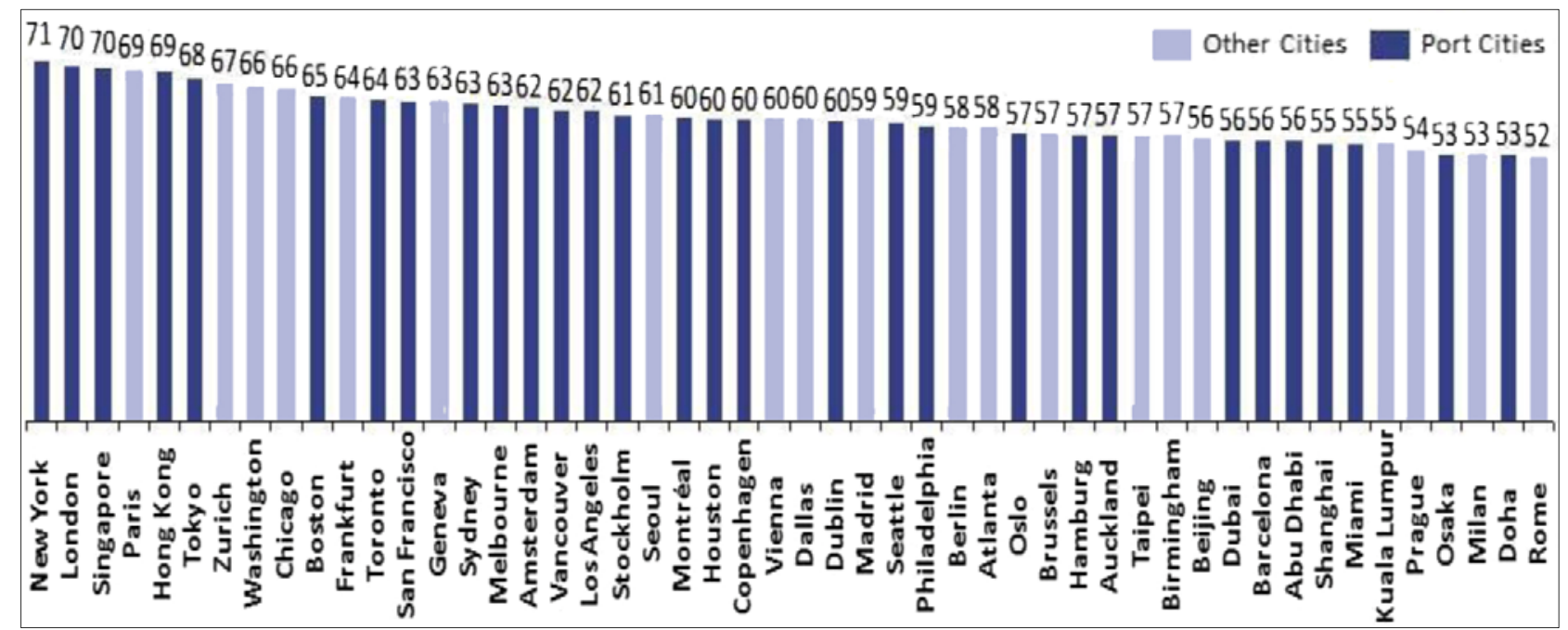

Source: The Economist—Economist Intelligence Unit (2012).

In the top 20 cities ranked according to the Human Capital Indicators, we can see that 14 are port cities (Figure 3).

Figure 3. Cities' human capital (population growth, working age population, entrepreneurship, quality of education, quality of health care, etc.).

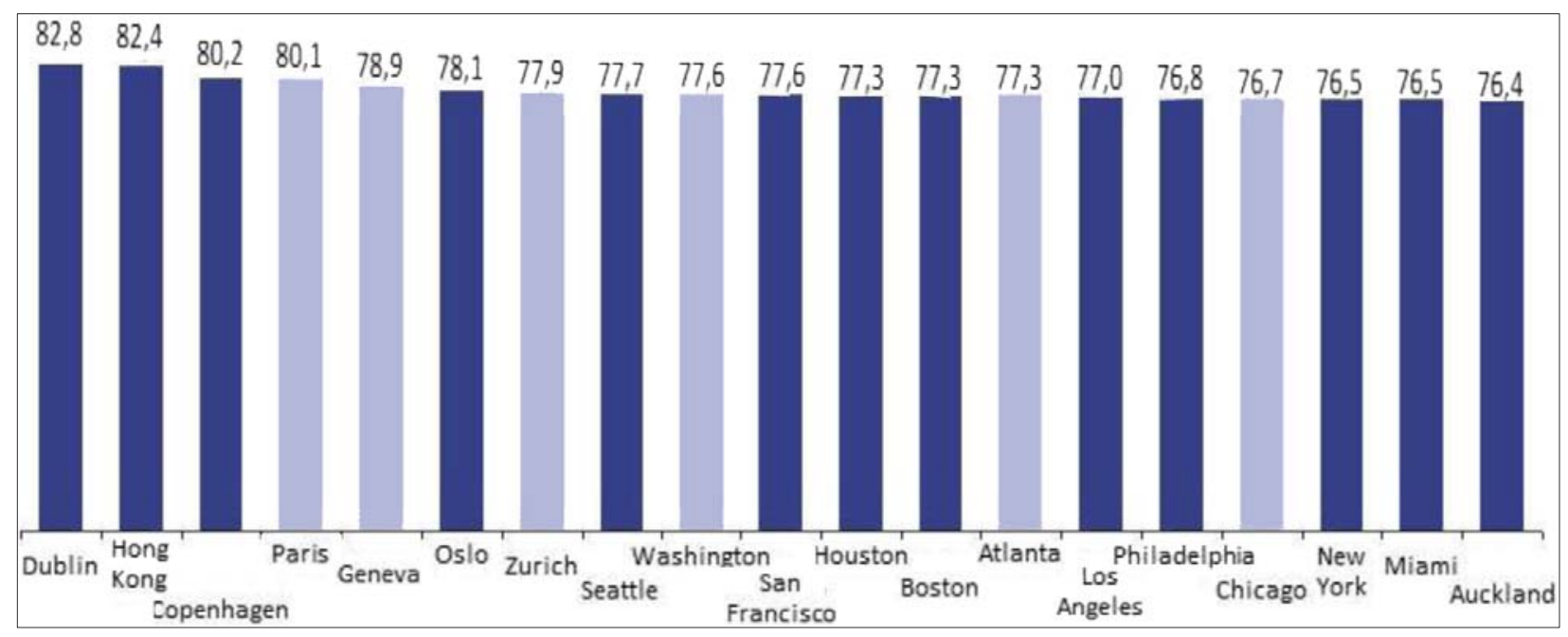

Source: The Economist—Economist Intelligence Unit (2012).

The "global appeal" appears to be concentrated in 7 of the 9 most globally "appealing” cities; these are port cities (Figure 4).

Port cities [3] are particular points for trade of imports and exports, a space of localization for many industries and services, and attractive areas for tourism and for cultural exchange. Port cities have always been cosmopolitan places, open to many cultures, with different ways of life and of working. They are historical spaces of creativity/innovation in the economy, in culture, in society, and all this is reflected in a specific architectural landscape. 
Figure 4. Global appeal (Number of Fortune 500 companies, Frequency of international flights, Number of international conferences and conventions, Global leadership in higher education, globally recognized think tank).

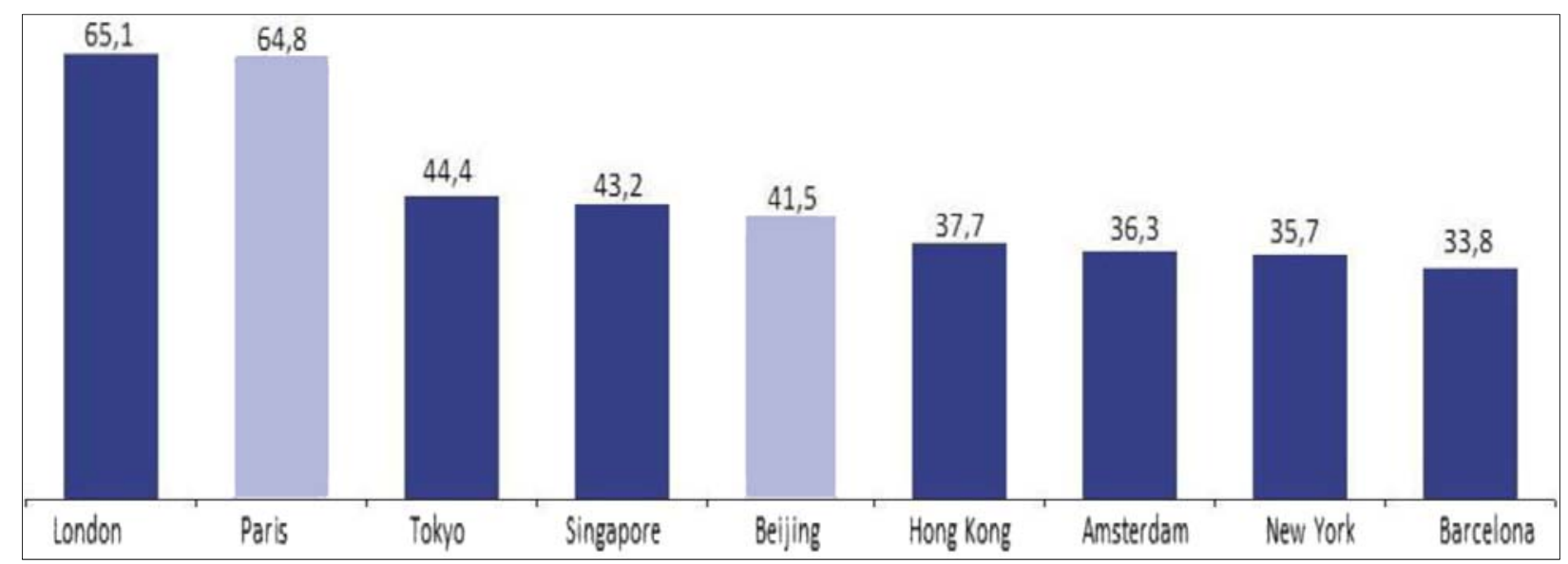

Source: The Economist_-Economist Intelligence Unit (2012).

However, they are also places of conflict between economy and ecology. Some conflicts [3] are generated by negative environmental impacts, due to the high level of energy consumption, air and water pollution, or natural resource consumption. Other conflicts are generated by the effort to conserve a specific cultural landscape and to meet the needs of economic development.

New approaches [3] and new tools are required to plan and manage conflicts, thus transforming differences in complementarities into a win-win perspective or into a synergistic perspective [4].

The smart sustainable city is a city where economic [3], social and environmental values are achieved in an efficient and balanced way, able to last over time. A general characteristic of a smart sustainable city is the capacity to contribute to closing the flows of resources through circularized processes and to activate synergies between actor or institutions in a win-win perspective.

\subsection{Port Areas}

Port areas are the "interface" between the city and the sea. Here the processes of economic globalization started already early in the history. It is here that most of the flows of the globalized economy arrive at and depart from. Ports are the nodal points connecting Europe, Asia, Australia and America in a mutual cooperative and competitive process, aimed at improving the benefits of their strategic localization. In fact, ports are a driving force of economic wealth, because commercial, industrial, logistic, tourist and fishing activities are localized here. They are a "magnet" for induced activities and, in turn, can also be an "incubator" for new services/activities. Ports, because of their central urban position, have a high economic and real estate potential. At the same time, port areas offer a particular landscape, which is the product of a complex system in which socio-cultural, economic and ecological systems are dynamically intertwined.

The presence of a particular landscape is a key characteristic of port areas. This landscape is recognized by the European Union [13] as an important economic resource in the global competition. Many of the most beautiful urban landscapes are port areas: Amalfi, Amsterdam, Venice, Genoa, Naples, Syracuse, Malta, Liverpool, Bergen, Istanbul, Saint Petersburg, Oporto, etc. In these cities, the 
historical center often reaches out to the seaport. Ancient city boundaries often coincide with port areas, where old warehouses, silos, wharfs, industrial archaeology heritage and lighthouses are situated and contribute to building a particular character, image and landscape. Historic port areas contribute to the particular beauty of the landscape, which expresses the combination of human and natural creativity and characterizes the true identity of a city: its unique image, but also its lifestyle and culture.

The beauty of port area landscapes is connected to its architectures, shapes, historic values, local materials, colors, microclimate, light and life. It builds the real image of a city, its "places", its soul. The "spirit of places" is sometimes linked to port areas. Sometimes port areas are particular urban places, which should be carefully maintained and valorized.

Beauty is an attribute of "places", which is the result of a creative process through time: they express what survives in the continuous transformations of urban structures $[14,15]$, which is the element of continuity in the ever-faster dynamism of cities.

\subsection{Conflicts in Port Areas/Cities}

Many paradoxes characterize nowadays port cities/areas. Environmental deterioration [3] and pollution processes often affect them. The production of their economic wealth implies high ecological, and also social and cultural costs. Often the port becomes a driver of environmental deterioration and reduced well-being for urban life; a place to avoid rather than a place to go. Here, old and new industrial activities have been localized: steelworks, chemical industries, shipyards, oil refineries, assemblage/transformation/construction activities, power plants, degasification plants, waste management equipment, etc. The logistic revolution, with ICT innovations, with automation and robotization and new technologies, has multiplied the quantity of goods and people in transit.

Ports produce [3] a lot of waste resulting from harbor industries, maintenance, dredging, navigation, etc. The negative externalities resulting from industrial/trade activities in ports do not just cause environmental damages, but are interconnected with the economic and social system in a negative way; they are a source of new economic (and social) damage for the whole city system. The development of the port/city system tends to become less and less sustainable. The economic benefits of port activities, once the ecological/environmental and social costs are subtracted-i.e., the "net benefits"-are sometimes lower than it would seem. Moreover, they do not benefit directly urban inhabitants, but often only a few trade/industry/tourism agents: that is, the benefits are not distributed equally among the various stakeholders. But port areas, as the main spaces where these contradictions/paradoxes come into being, are also the most suitable sites to reduce conflicts and to transform these into synergies, provided that innovative approaches of governance, at a strategic, planning and management level, are implemented. They can become the entry point for a sustainable development of the whole urban system if creativity and resilience are really promoted in managing this particular complex system, through specific creative actions. In fact, port areas [3] are the sites where "differences" among cultures, architectures, or ethnic groups have always been deep. These "differences" have fostered a favorable atmosphere to new "openings", creativity and innovation in different fields: artistic, scientific, management, etc. [16]. The potential of creativity, which is higher in port cities than in other cities, is the element that can help overcome conflicts/contradictions. 
It is thus not by chance that all over the world port areas have become sites where actual creative actions aimed at promoting sustainability are often implemented. Investments in the urban regeneration of waterfronts-in Rotterdam, Barcelona, Liverpool, Valencia, Vancouver, Tokyo, Hamburg, Malmo, Amsterdam, Genoa, Glasgow, Antwerp, Copenhagen, etc.- are well-known experiences. They can be interpreted as "transition experiments" [17]. They express the creativity and also resilience of cities against the pressures of change, by highlighting the capability of cities to transform themselves and to maintain their identity.

\section{Towards a More Efficient and Less Dissipative City Organization: The Circular Model}

A more efficient and less dissipative [3] organization of city processes is required in order to face not only the globalized economic competition, but also the energy challenge, the social challenge, and the ecological challenge. They are all based on circular and synergistic processes [2]. This development strategy should integrate hard and soft values/objectives (that is, both economic and social/environmental, as well as landscape preservation) in a win-win game. It may contribute to city resilience, which is the capacity of the city to react and manage change, maintaining its comprehensive organization and structure. Clearly, this process is not based on traditional industry and real estate economics (as often happens for port areas), but on ecological economics: on use and non-use/“intrinsic” values [18], on a long-term perspective, with the aim of realizing a new metabolism in the port areas and spreading it to the whole urban system. It is a "creative" strategy, because it integrates the economic wealth production (business) with ecological preservation and reduction of social marginalization, starting from the ancient historical roots, in a win-win perspective; it "integrates" industrial, commercial and tertiary activities with those relating to culture and knowledge and thus it improves the landscape, the "atmosphere", and the identity; in other words, the image of port areas. A port areas’ smart development should be based on circular processes at three main levels:

(1) Economic [3]: symbiosis between companies for value creation, allowing synergies and also stimulating circuits between company and community prosperity [19]; between companies and the city; between all actors and the outside territory;

(2) Social: able to regenerate interpersonal relationships-often weakened in cities — through relationships with "places";

(3) Ecological: all living systems are characterized by circular processes and are able to conserve and reproduce themselves. Circular processes emerge through re-use, recycling and regeneration of materials and energy, with a reduction of negative externalities. The resilience of systems and creativity are stimulated by circular processes, which break down linear metabolism.

Harbor areas become vital, when they act as dynamic, complex systems, capable of transforming and adapting to the continuous pressure of change from the outside and when they are able to modify their physical structure regarding space, organization and functions, by combining infrastructures, facilities, installations, etc., while maintaining their own identity. Here, green industrial activities, able to decouple economic wealth production from ecological losses, should be grounded while considering the model of living systems. 


\section{The Key Role of Architecture and Planning}

Architecture and urban planning can contribute to an enhancement of the quality of urban space. Architecture can improve the "atmosphere" and the landscape, because it gives a characterizing image to ports, which may became a brand for the whole city. At stake is the relationship between the old and the new, between tradition and modernization, resulting in the ability to make the whole city "more attractive”. The relationship between the ancient and the new is clearly delicate: modern architecture constructions can seriously damage the aesthetic value of cultural and historic landscapes, existing ecosystems, etc.

By means of a high-quality architecture projects and planning, the urban landscape is preserved, enhanced and created [13]. Real creative architecture produces "places” and not only marketing tools to multiply real estate value and business. It contributes to preserving the character and the atmosphere of a place without twisting it exclusively for commercial, functional or economic needs. It stimulates real life, not only events: communication among people, face-to-face relationships, symbolic values, which stimulate aggregation capability, sense and feeling of belonging, and collective identity. If architecture joins planning and management, port areas are places that may become the starting point for innovative local development strategies within a systemic perspective, based on the circular approach, for reducing/eradicating waste. The eco-town model or the eco-city model may then become a key perspective for urban strategic planning. Planning and design become then also key tools to implement in the concrete physical space the above model, aiming at increasing the prosperity of the city.

\section{Good Circular Model Practices in Port City Economic Systems}

\subsection{Good Practices in Resources Regeneration}

A general characteristic of a sustainable city is the capacity to close resource loops through circularized processes, which are able to reproduce/regenerate original capital stocks, able to last over a longer time period. In this way, cities can become the key for implementing a new sustainable development model based on many parallel value creation systems, centered on a synergistic approach [2]. The circularization in an industrial system has a positive impact on costs and employment, breaking the current linear ("take, make, dispose") organization of many economic systems. Economic circuits are shortened and the local economy is strengthened through integration.

\subsection{Circular Processes in Industrial Port Cities}

Examples of good practices that have been implemented through industrial symbiosis, can be found, inter alia, in Japan, China (Shenyang), and in Europe [3]. For example, in Japan, 26 eco-town areas were identified to implement a circular model in port cities, starting from 1996 (see Figures 5 and 6) [20]. 
Figure 5. Japanese eco-towns strategy to circularize the industrial city system, with positive outcomes for the environment.

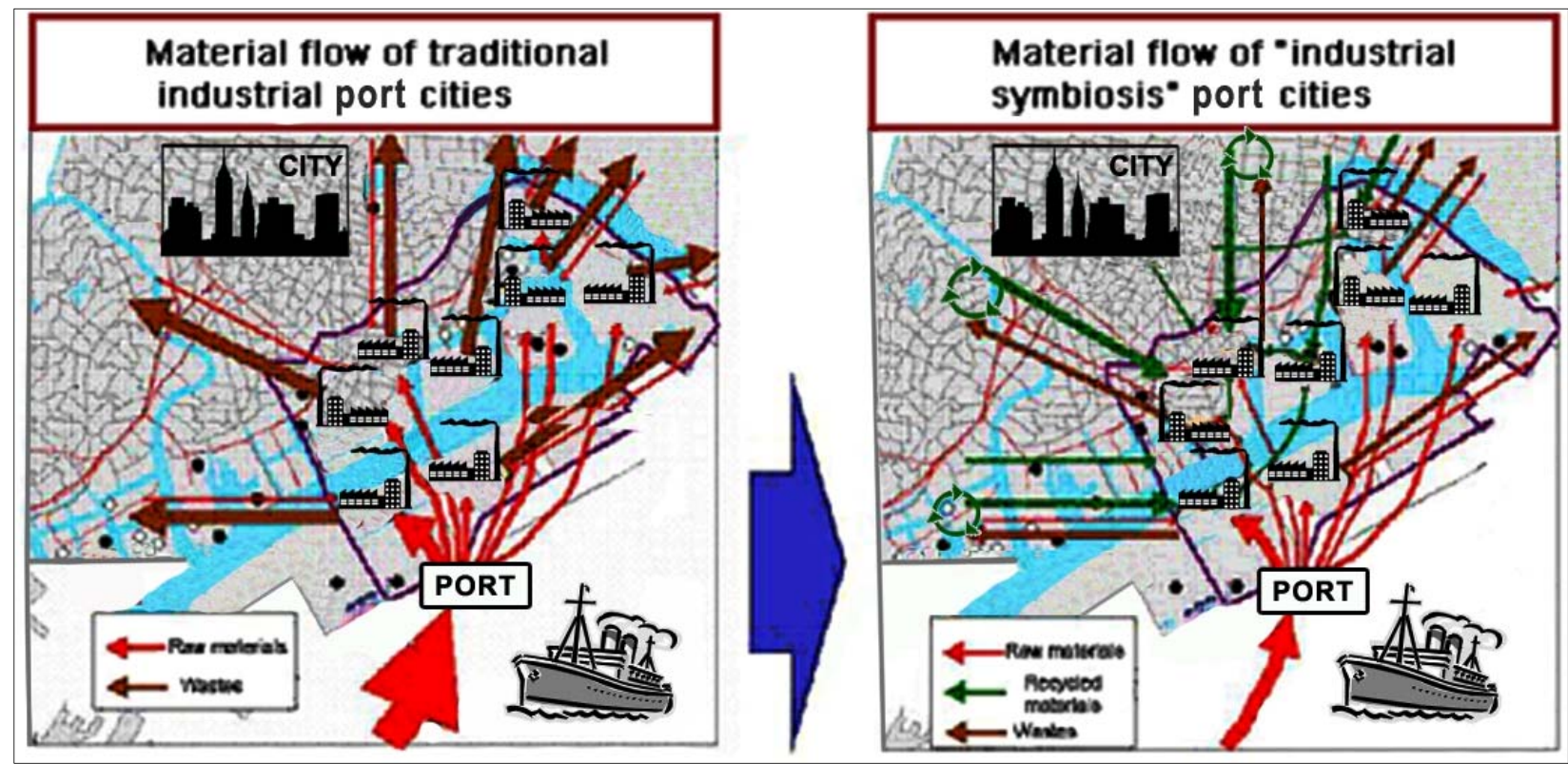

Source: adapted from Fujita (2012) [21].

Figure 6. The circular economic port city system.



Source: adapted from Fujita (2012) [21].

The lessons from this circularization process can be summarized as follows [21]:

- Industrial symbiosis has been a driver for new sustainable eco-industrial developments and low carbon industrial systems;

- Waste management systems have played a crucial role in supporting circular business;

- Urban symbiosis and a regional eco-industrial clustering network may provide more business opportunities. 
Some other interesting experiences on circularization processes can be found in European port cities [22]. For example, in Swansea, about 700 hectares were declared as the most polluted in the UK because of the industrial copper activity. During the 1970s, a comprehensive reconstruction of this ecosystem was implemented, regenerating the environment and the landscape and thus attracting new economic activities [23].

In North America, one of the most polluted port areas was in Hamilton (Canada), because of the existing steel and other related industrial activities. Through a strategic plan, the land was decontaminated and a new attractive environment was constructed with a strong participation of all city stakeholders.

In all these cases, the circular and synergistic principles have been implemented in city planning, by reshaping it and by ensuring the participation of all actors.

\subsection{Circular Processes in the Heritage Economic Systems}

Other good practices that introduced elements of circularization in the context of industrial heritage can be found, for example, in Dublin, Liverpool, and Hamburg. There are also practices more directly related to the ECoC (European Capitals of Culture) programme. Other experiences can be found in cities belonging to "Slow International City Network" and "Transition Towns Movement" and also by the "Nuovi Municipia Network" and "Virtuous Cities Network" (in Italy). Some of them are also touristic port cities. They have shown interesting experiences in which "circular processes" (activated through an integrated conservation of cultural heritage/landscape) have contributed to the resilience and sustainability by stimulating people's creativity.

"Slow city" strategies can be interpreted as a particular "smart" city development strategy. They are based on the reconstruction of a specific identity, which stresses the differences among geographical localizations. Some of them have transformed cultural heritage and landscape conservation into economic wealth production, starting from "places", thus contributing to economic sustainability [24-26]. They have promoted the creation of local communities that take care of "places", thus becoming more responsible and resilient, contributing to social sustainability.

In many of these approaches, city/heritage capital has been recognized as the starting point to increase economic prosperity, environmental quality and social conviviality, since conservation of cultural heritage has been regarded as a productive activity. City history, memory and identity have been conserved in a creative way, combining conservation with innovations, past and present, present and future, within a circular process.

Conserving "places" in a productive perspective has been interpreted as a valorization process, creating an added value (in terms of use values, social values, symbolic values, market values) through circularization and synergies. In the new “circular” heritage economy, import capability (attractiveness for tourists, visitors, talents, capitals) and export capability (handicraft products, arts, local identity products, knowledge products) are integrated into wealth-creating processes. Re-use, restoration and regeneration of materials stimulate circular processes. Cultural heritage is often considered as the incubator of new creative activities, which are usually found in cultural districts.

Tourism development is also often considered as an "instrumental" vehicle towards a richer knowledge-led economy, able to produce new jobs related to new local activities, arts production, new 
cultural/social networks, new scientific/arts/design products, and in general to the capacity to export intellectual/knowledge products. In these practices it is possible to identify interesting contributions to the circularization of processes and to stimulate synergies between city subsystems, actors and knowledge specializations.

The lesson from the above expositions is that the integrated conservation of cultural heritage can play a key role in promoting a circularization of city processes, and thus in enhancing the cities' resilience and creativity. In some experiences, integrated conservation has contributed to turning linear chains into circular relationships, to closing the loops of resources and flows, by stimulating other parallel cycles of value creation, in particular, social, ecological and cultural loops [27,28].

The success of integrated conservation (in terms of resilience, creativity and sustainability) can be measured by the density of circular processes and synergies that have been activated in a specific area/territory (see Figure 7 and Table 1).

Figure 7. Circular processes in a heritage economic system [3].

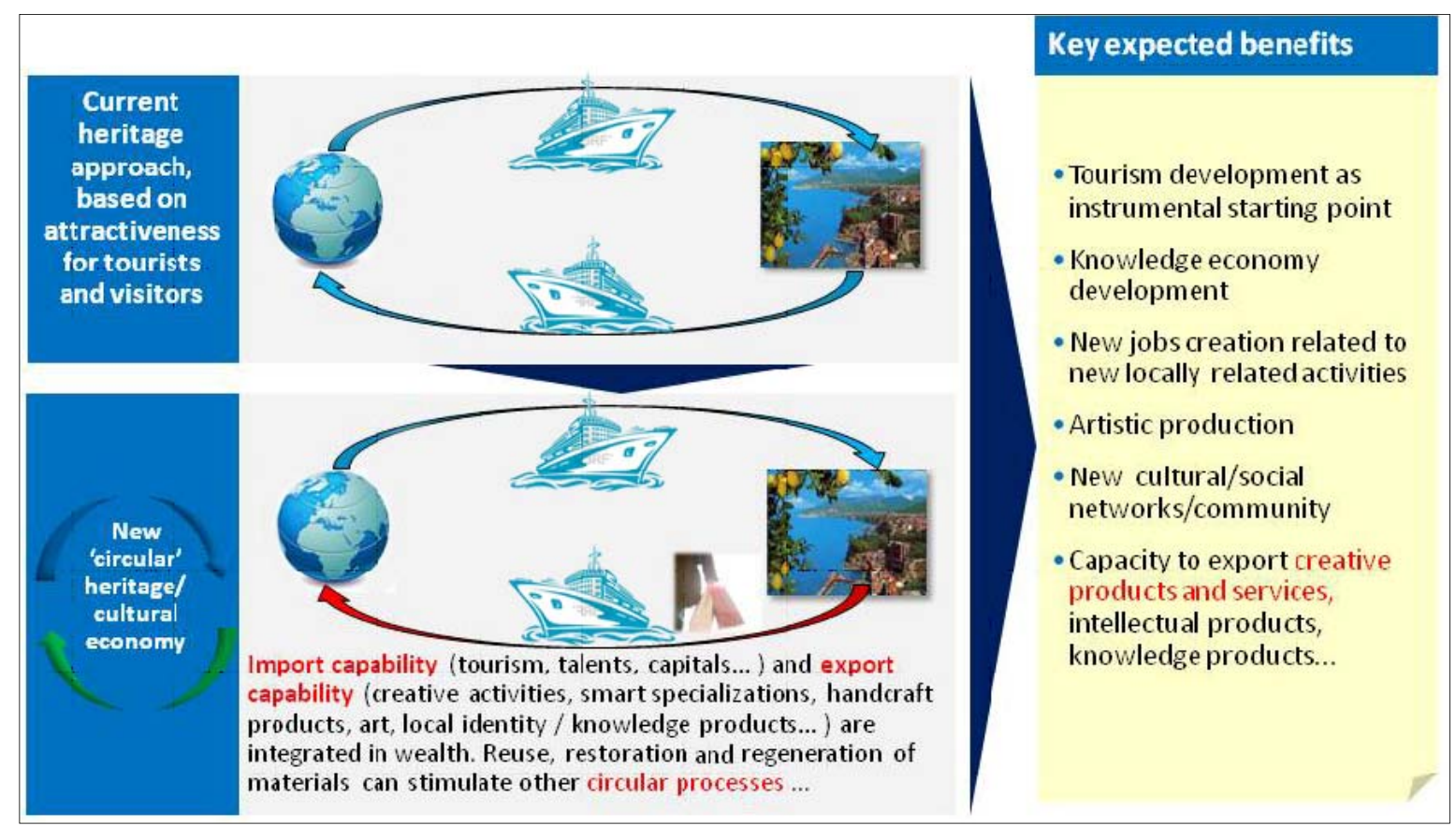

\section{Proposal of a Circularized/Synergistic Smart Development Model in Port Cities/Areas}

It is no doubt meaningful to integrate in port cities/areas the industrial circularized system offered by some good practices [3] (see Subsection 4.2) with the circularized processes of heritage/culture economy (see Subsection 4.3), based on a social economic system (Figure 8).

Port areas can be considered as the departure for a new economic city organization that reduces material inputs, waste, energy consumption and carbon emissions, connects port areas to the whole city system and stimulates pilot experiments in businesses as well as in architecture/planning, based on a "circular" design [29-31]. Port cities import, through harbor infrastructures, all kinds of waste from outside; they process them through innovative green technologies and thus export outside treated materials (iron, copper, paper, aluminum, plastics, etc.). 
Table 1. The role of cultural heritage-integrated conservation, towards circularization and synergies [3].

\begin{tabular}{|c|c|c|c|c|}
\hline & & \multicolumn{3}{|c|}{ Quantitative/Qualitative Impacts } \\
\hline & & Economic & Ecologic & Social \\
\hline \multirow{3}{*}{ 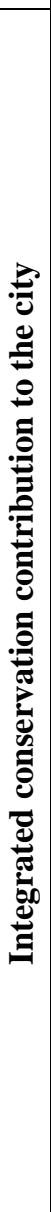 } & نُّ & $\begin{array}{l}\text { Heritage conservation has been } \\
\text { interpreted as recreation of } \\
\text { places, by innovative activities/ } \\
\text { processes. They have guaranteed } \\
\text { the financial investments payback } \\
\text { and stimulated new investments in } \\
\text { circular perspective, attracting } \\
\text { creative entrepreneurs and } \\
\text { increasing local productivity }\end{array}$ & $\begin{array}{l}\text { The introduction of green } \\
\text { technology in heritage } \\
\text { conservation: } \\
\text { - has reduced the ecological load } \\
\text { - has stimulated new economic } \\
\text { processes based on circular loops }\end{array}$ & $\begin{array}{l}\text { - Innovative management models } \\
\text { able to link build cultural } \\
\text { heritage to people/inhabitants, } \\
\text {..promoting community } \\
\text { through circular relationships } \\
\text { - Interactive creativity processes } \\
\text { through strong participation }\end{array}$ \\
\hline & 苞 & $\begin{array}{l}\text { A local economy based on } \\
\text { short loops between production } \\
\text { and consumption on the use of } \\
\text { local resources, can become } \\
\text { more resilient to facing } \\
\text { globalized economy stresses. } \\
\text { Valorization of local diversities } \\
\text { increases resilience }\end{array}$ & $\begin{array}{l}\text { Reuse, recycling, restoration } \\
\text { and regeneration of natural } \\
\text { materials contribute to: } \\
\text { - co-evolution of urban and } \\
\text { ecological systems } \\
\text { - city mitigation and adaptation } \\
\text { plans } \\
\text { - circularization of processes }\end{array}$ & $\begin{array}{l}\text { - Through valorization of the quality } \\
\text { of the physical environment the } \\
\text { places attractiveness is increased, } \\
\text { and the competitiveness, with } \\
\text { positive outcomes for jobs, wealth } \\
\text { production and distribution, } \\
\text { reducing poverty and reinforcing } \\
\text { social bonds with circular } \\
\text { relationships }\end{array}$ \\
\hline & 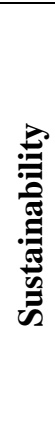 & $\begin{array}{l}\text { Regeneration of historic districts } \\
\text { has valorized resources of places } \\
\text { (history and geography) } \\
\text { characterized by specific identity } \\
\text { and has attracted people and } \\
\text { investment, and stimulating local } \\
\text { entrepreneurship has increased } \\
\text { the capacity to export new } \\
\text { quality goods services, in a } \\
\text { circular/synergistic process }\end{array}$ & $\begin{array}{l}\text { Reduction of natural resources } \\
\text { and fossil energy to satisfy } \\
\text { human need has contributed to: } \\
\text { - the health of the ecosystem and } \\
\text { to human health } \\
\text { - quality of life } \\
\text { - urban synergies based on } \\
\text { circularization/relationships/con } \\
\text { nections }\end{array}$ & $\begin{array}{l}\text { - Places regeneration can be } \\
\text { considered as the entrance point } \\
\text { towards self-organization of the } \\
\text { district } \\
\text { - Common resources management } \\
\text { stimulates the self-management } \\
\text { potential of local communities } \\
\text { towards a self-sustainable } \\
\text { model that is characterized by } \\
\text { itself by circular relational } \\
\text { dense relationships }\end{array}$ \\
\hline
\end{tabular}

The role of the social economic system is to become the engine for sustaining in a bottom-up way the new circular and synergistic smart development model. A social economic system is characterized by value creation processes that are different from conventional economic ones. It is able to increase cultural resilience, because it produces, in its exchanges, virtuous circular processes: reciprocity, social responsibility and public spirit. In other words, a social economy replaces/regenerates the social capital that makes the economy and democracy work. It stimulates circularity processes as well as the employment and care of ecosystems. A social economic system is both auto-poietic (based on circular processes) and hetero-poietic, and thus able to sustain other systems. It is structurally characterized by a circular and synergistic organization. In fact, it includes community associations, voluntary groups, civic society networks, and formal and informal organizations, which are independent of the government and are self-governing (e.g., housing associations, charities, social enterprises, etc.) whose surpluses are principally reinvested in the production of goods and services, to better satisfy the needs of the community. It sustains in a bottom-up fashion heritage and an industrial circular economy. 
Figure 8. Towards a new circular synergistic economic model for port cities.

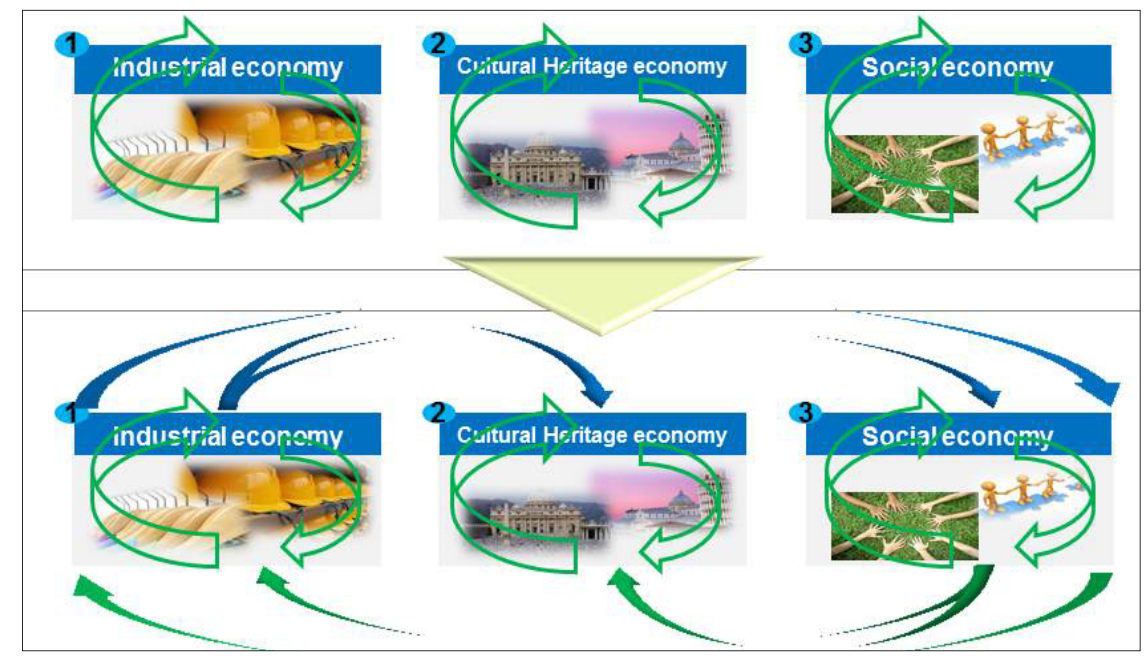

\section{The HUL Approach to Managing Change towards a Circular/Synergistic Model}

The Historic Urban Landscape (HUL) approach brings heritage conservation to a new visioning that links tradition and modernization, past and present, present and future in a systemic/circular and synergistic perspective.

The HUL approach proposes, first of all, a way of thinking urban initiatives in a multidimensional space, stressing the attention to interdependences and relationships between the different aspects and the whole. It reflects a unifying cultural perspective based on the principle of Relationality. The principle of Relationality is reflected in the ability to explore/understand complex systems recognizing interdependences, links, connections, also when they are implicit; assuming a multidimensional point of view; it is a way to interpret reality in a comprehensive/holistic perspective that does not exclude, but integrates economic, aesthetic/visual, fairness aspects and values, etc.

The implementation of HUL is linked to the capacity to relate to, to compare, and to critically evaluate. It is based on the capacity to integrate economic rationality into relational rationality. In the HUL approach the interpretation of conservation is oriented towards respecting the integrity of values and avoiding alterations of values, but assuming a general changing perspective [32]. The city is the central subject, and not the single set of monuments: the city as a "social complex" and as a "living heritage"; that is, the city is a complex adaptive system.

The consequences of the interpretation of cultural heritage as a subsystem of a city's complex dynamic and adaptive system is that cultural heritage should evolve with society, reflecting its changes, adapting itself to the new needs of inhabitants, in a circular way. The HUL approach, recognizing links, relationships and connections, can be interpreted as an indirect leverage for circularizing the traditional economic model (starting from a cultural heritage economy) and for promoting synergies between different agents/institutions. It proposes a creative integration between conservation and development, from a dynamic and proactive perspective. It stresses the need to conserve the original identity, but it considers change as something to be managed in a dynamic perspective, in order to fully satisfy the people's needs. HUL contributes to increasing the impacts of the conservation of cultural heritage in terms of creativity, resilience and sustainability, because of its 
systemic nature, and is very useful to stress the integration of heritage conservation into city planning, breaking the prescriptive approach of conservation charters [32], in a more flexible and evolving perspective. In this view, conservation of cultural heritage becomes a productive activity, able to increase values in multiple dimensions.

In particular, HUL is oriented towards managing changes by combining adaptations with continuity, towards a change/increase of: use values, market values, social/relational/communitarian values, cultural values, spiritual values, etc. HUL, by stressing innovation in conservation (interpreted in a dynamic perspective), opposes standardization, focuses on creative conservation for effective development (not just linked to tourism) and stimulates new synergies (e.g., between ancient and new, economy and history). The HUL approach requires a sustainable management system in urban areas for managing change.

The management system is a key element for conserving existing values and producing new (not already given) values with a recreation process of tangible and intangible values, and stimulates, through learning and interpretation, the metabolization of values.

The role of a HUL management system is to avoid conserved cultural heritage remaining only as a vestige of an ancient past, unable to transmit meanings and sense (which goes beyond the aesthetic dimension) into the present time. It stimulates circularization processes between commons (cultural heritage, landscape, etc.) and community (producing relational/glue values) and it promotes self-organization/self-management capacity (transforming cultural values into civil values), by turning conflicts into synergies. It opens up a systemic/holistic perspective to city challenges.

The implementation of a HUL approach in port areas stresses the "productive" interpretation of heritage conservation, by stimulating new creative activities (see Table 1). More generally, it is able to integrate the circularization of a heritage economy into a comprehensive synergistic economic model. Thus the HUL approach forms the guarantee that the transition toward the smart city development model is based on specific local culture resources, and not only on technological innovations: the eco-town/eco-city strategy becomes culture led, i.e., based on the "integral use of cultural resources in urban development” [33] (see Figure 9). Moreover, the HUL approach not only stimulates synergies and circularization processes in concrete spaces/places of cities [34] to achieve the greater good for all the actors(enhancing quality of life, productive efficiency conditions, sense of identity), but also stresses the need to identify new tools for supporting economically urban changes.

Figure 9. Smart sustainable city development, innovation and culture [3].

Smart City Sustainable Development




All squares, historic architectural assets, local characteristic warehouses, or buildings of specific quality become spatial platforms for a creative environment, in which the "Triple Helix Model” can be concretely implemented. Here, many different actors can meet and cooperate together, thereby communicating and exchanging knowledge/experiences, and are reciprocally fertilizing toward a “cumulative development spiral”.

Innovative income generation can come from capturing a percentage of market plus-value generated by change and transferring it from private owners to public body, in a "circular" process [35].

The implementation of HUL requires not only technical tools, but also a strong intellectual and critical process of interpretation and mediation between multiple conflicting forces, in search of an equilibrium/balance, matching different stakeholders' interests: private and public needs, and in particular building entrepreneurs' interests (profitability, market values, costs...), with local inhabitants' interests/needs (low-cost residential services, access to other services ...), with general interests and the needs of all city inhabitants.

The success of HUL implementation depends on strong support from bottom up: on a strong city cultural base, which stimulates cooperative approaches, and a circular way of thinking, toward the achievement of the city's general interest.

\section{Specific Tools for Managing Change}

Some questions arise. How can we operationally manage changes in this dynamic urban port perspective, attentive to conserving integrity, identity and continuity? [3] How is it possible to reduce the negative impacts of change toward an acceptable level? [22] Which tools should be used to monitor changes and to identify priorities, between preservation of values and satisfaction of social needs, improving well-being? How to develop policies at the interface of the static perspective of conserving existing values and the introduction of modernization in the life of a city or between maintaining values that are already given and producing new values?

HUL requires specific tools for managing change, bringing choices closer with the whole community (with Living Lab processes etc.). In particular, it requires new tools for evaluating different alternatives based on their multidimensional impacts: new systemic approaches and new indicators should be introduced. For example, Heritage Impact Assessment [36,37], Landscape Impact Assessment, Visual Impact Assessment, Cultural Impact Assessment, etc. should be reunited into a more general "spatial integrated evaluation strategy" to identify limits to acceptable change and to manage smart sustainable changes: to assess landscape value change due to new volumes of malls, tall buildings, new roads etc. and to evaluate, through specific indicators, the "absorption capacity" of a specific landscape.

The economic approach can be the main leverage in defending landscapes, if soft values (such as visual landscapes cultural values, etc.) are converted into monetary values. The modern economic approach in evaluation through willingness to pay is able to better communicate values, in particular the value changes coming from different actions on cultural landscape. Clearly, a single economic approach, even through necessary, is not sufficient to identify such limits to change [38].

Multi-criteria multi-group evaluation techniques are a key tool in the management and comparison of positive and negative impacts, to balance and to compensate different impacts for all involved 
stakeholders (Public, Private, Financial, Social, Civil). In this context, economic, social, environmental, cultural, symbolic, quantitative and qualitative, short- and medium-long-term perspective impacts are to be assessed and compared to deduce priorities for actions [39-41]. In addition, new approaches and tools to improve the assessment of the use value of rare and unique landscape resources are required, according to the complex social value perspective [15,18,42-45], to assess the change and its attractiveness capacity. An example of indicators research in terms of new established business, or produced incubation activities, etc. is proposed by KEA for assessing investments in cultural and creative assets [46]. They should be integrated into a more general landscape resilience set of indicators [15].

An evaluation culture, interpreted as a shared critical knowledge (able to distinguish, foresee, put into perspective, compare for deriving priorities), does not only concern experts but also all inhabitants of the city. They should participate in strengthening assessment through dialogue, discussion and debate. Without these tools and this widespread "evaluation culture", the risks in implementing HUL are very high.

\section{Conclusions}

Industrial-commercial and tourist port areas are spaces of differences, rich in potential opportunities but also in contradictions and conflicts. Their landscape is a very important local resource for urban and regional smart development. Ports, maritime transports, logistic divisions as well as tourism/pleasure activities are all characterized by an increasing potential growth. Their sustainable smart development depends on the valorization of their diverse characteristics, in a general context. Port areas are increasingly becoming new spaces where creativity is, and can be, practiced.

A smart sustainable development can start from the port areas' new circular metabolism [15] which should be extended to the whole city/region, thus modifying the land and space use through new efficient planning and design able to increase the comprehensive quality of the urban landscape. This integrated smart development model, supported by urban planning, contributes to urban ecological resilience.

In addition, the conservation-recreation interface of urban cultural heritage contributes to resilience and prosperity, insofar as it stimulates cultural identity and the sense of place. In turn, enhancing the urban cultural landscape through planning/design promotes the general milieu that stimulates urban creativity. Clearly, creativity, resilience and sustainability principles are incorporated in the HUL systemic notion and are strictly linked together.

The HUL approach stimulates circularization/synergies in managing change of port cities/areas for their regeneration, promoting places as spatial specific "loci", where to meet, communicate, and exchange knowledge and practices among different actors.

ICT and innovative technologies are certainly to be introduced rigorously to implement circularization and synergistic processes. However, they also require a culture base. The city culture is reflected in the ways people live and work [47] and in the linear or circular way of thinking of all city agents, opening a perspective to a multidimensional space, attentive to interdependences and connections.

HUL, linking the old with the new, past and present, present and future, intrinsic values and instrumental values, private spaces and public spaces, and a conservation project and management 
model, puts from a circular perspective all aspects in a holistic/systemic view. It stimulates a cultural planning approach to local development. In general, it promotes a transdisciplinary perspective, attentive to both the part and the whole, to specific interests and to common goods. HUL can be usefully implemented towards smart sustainable development of port cities/areas, which may become the entrance point to an urban comprehensive regeneration process, founded on a new metabolism. Altogether, HUL stimulates creative and resilient solutions to be identified at strategic, planning, design and management levels to implement smart sustainable wealth recreation of cities. New tools are clearly necessary to implement HUL.

Evaluation [3] of best/good practices and pilot experiments are to be considered as a first step towards new knowledge production on the basis of specific indicators. Evaluation allows economic, social and environmental feasibility to be assessed by interpreting, forecasting and comparing different multidimensional impacts. Evaluation promotes also new partnerships, new management and competitive capacity initiatives. Through an integrated evaluation it is possible to identify a ranking of various alternatives with different levels of change in the port area landscapes, which determine different levels of attractiveness, by considering multiple, multidimensional and conflicting criteria. A critical element is the availability of adequate knowledge: not only data, information, GIS, etc., but a generalized knowledge [47] derived from concrete practices. Many indicators are necessary to assess the outcomes, the efficiency and effectiveness of synergies and circularized processes [48].

An evaluation of best (and worst) practices is crucial for extracting generalized knowledge, needed for a vital and innovative project, which aims to transform port cities/areas into new attractive and prosperous "places". Through adaptive evaluation processes, it is possible to re-interpret the complex landscape of harbor cities/areas and to propose new plans, projects and management programs, trying to transform the "spirit of the place" into a local sustainable development engine.

\section{Conflicts of Interest}

The author declares no conflict of interest.

\section{References}

1. Flint, J.; Raco, M. The Future of Sustainable Cities: Critical Reflections; The Policy Press: Bristol, UK, 2012.

2. Ravetz, J.; Fusco Girard, L.; Bornstein, L. A research and policy development agenda: Fostering creative equitable and sustainable port cities. Bollettino del Dipartimento di Conservazione dei Beni Architettonici ed Ambientali 2012, 12, 67-69, (in French).

3. Fusco Girard, L. The urban future. Bollettino del Dipartimento di Conservazione dei Beni Architettonici ed Ambientali 2012, 12, 19-34, (in French).

4. Ravetz, J. New future for old ports: Synergistic innovation in a global urban system. Sustainability 2013, 5, in press.

5. Ravetz, J. Urban Synergy Foresight. In Urban Governance in the EU; EU Committee of the Regions: Brussels, Belgium, 2011; pp. 31-44.

6. Geddes, P. Cities in Evolution; Williams \& Norgate: London, UK, 1915. 
7. UNESCO. Recommendation on the Historic Urban Landscape; UNESCO World Heritage Centre: Paris, France, 2011.

8. Hein, C. Port Cities: Dynamic Landscapes and Global Networks; Routledge: London, UK, New York, NY, USA, 2011.

9. Schubert, D. Seaport Cities: Phases of Spatial Restructuring and Types and Dimensions of Redevelopment. In Port Cities: Dynamic Landscapes and Global Networks, 1st ed.; Hein, C., Ed.; Routledge: London, UK, New York, NY, USA, 2011; pp. 54-69.

10. Ward, S. Port Cities and the Global Exchange of Planning Ideas. In Port Cities: Dynamic Landscapes and Global Networks; Hein, C., Ed.; Routledge: London, UK, New York, NY, USA, 2011.

11. Hayuth, Y. The port-urban interface: An area in transition. Area 1982, 14, 218-224.

12. The Economist Intelligence Unit Hot Spots. Benchmarking Global City Competitiveness. A Report from the Economist Intelligence Unit, The Economist. Available online: http://www.citigroup.com/citi/citiforcities/pdfs/eiu_hotspots_2012.pdf (accessed on 30 August 2012).

13. Council of Europe. European Landscape Convention; Council of Europe: Bruxelles, Italy, 2000.

14. Fusco Girard, L. Cultural tourism: From cultural fruition to cultural communication and production. Int. J. Serv. Technol. Manag. 2008, 10, 15-28.

15. Fusco Girard, L.; Baycan, T.; Nijkamp, P. Sustainable City and Creativity. Promoting Creative Urban Initiatives; Ashgate: Aldershot, UK, 2011; pp. 55-96.

16. Van Hooydonk, E. Soft Values of Seaports; Garand: Antwerp, Belgium, 2007.

17. Rotmans, J.; Loorbach, D. Transition Management: Reflexive Governance of Societal Complexity through Searching, Learning and Experimenting. In Managing the Transition to Renewable Energy; van den Bergh, J.C.J.M., Bruinsma, F.R., Eds.; Edward Elgar: Cheltenham, UK, 2008; Chapter 2, pp. 15-46.

18. Fusco Girard, L. Risorse Architettoniche e Ambientali (in Italian); FrancoAngeli: Milano, Italy, 1987.

19. Porter, M.; Kramer, M. Harvard Business Review: Creating Shared Value. Available online: http://hbr.org/2011/01/the-big-idea-creating-shared-value (accessed on 30 August 2013).

20. Van Berkel, R.; Fujita, T.; Hashimoto, S.; Geng, Y. Industrial and urban symbiosis in Japan: Analysis of the eco-town program 1997-2006. J. Environ. Manag. 2009, 90, 1544-1546.

21. Fujita, T. Eco Future Initiative in Japan as Challenges to Show Green Innovation from Cities-Industrial Symbiosis as Policy System for Circularization of Port Cities. In Proceedings of the Presentation Conference on Port Cities as Hotspots of Creative and Sustainable Local Development, Naples, Italy, 1-2 September 2012.

22. Fusco Girard, F. Symbioses strategies for sustainable company management. Int. J. Sustain. Dev. 2010, 12, 248-263.

23. Fusco Girard, L.; You, N. Città Attrattori di Speranza (in Italian); FrancoAngeli: Milano, Italy, 2006.

24. Baykan, T.; Fusco Girard, L. Case Study Window-Culture in International Sustainability Practices and Perspectives: The Experience of the 'Slow City Movement, Cittaslow'. In The Ashgate Research Companion to Planning and Culture; Young, G., Stevenson, D., Eds.; Ashgate: Aldershot, UK, 2013; Part 4.

25. Knox, P. Creating ordinary places: Slow cities in a fast world. J. Urban Des. 2005, 10, 1-11.

26. Mayer, H.; Knox, P. Slow cities: Sustainable places in a fast world. J. Urban Aff. 2006, 28, 321-334. 
27. Fusco Girard, L. Creative initiatives in cities. BdC. Bollettino del CentroCalzabini 2013, 13, in press.

28. Hopkins, R. The Transition Handbook: From Oil Dependency to Local Resilience; Chelsea Green Publishing: White River Junction, VT, USA, 2009.

29. Fusco Girard, L. Multidimensional evaluation processes to manage creative, resilient and sustainable city. Aestimum 2011, 13, 123-139.

30. Fusco Girard, L. For sustainable human development in the Mezzogiorno Region: how to manage the transition towards a new urban economic base? In North and South to 150 years from the Unification of Italy; Svimez: Roma, Italy, 2012; pp. 759-779.

31. Fusco Girard, L. Sustainability, creativity, resilience: Towards new development strategies of port areas through evaluation processes. Int. J. Sustain. Dev. 2010, 13, 161-184.

32. Bandarin, F.; van Oers, R. The Historic Urban Landscape: Managing Heritage in an Urban Century; Wiley: Hoboken, NJ, USA, 2011.

33. Mercier, C. Cultural planning for urban development and creative cities. Available online: http://www.google.com.tw/url?sa=t\&rct=j\&q=\&esrc=s\&source=web\&cd=1\&cad=rja\&ved=0CD YQFjAA\&url=http\%3A\%2F\%2Fwww.culturalplanning-oresund.net\%2FPDF_activities\%2Fmaj06\% 2FShanghai_cultural_planning_paper.pdf\&ei=X9FDUorwConjrAGaiYDoBQ\&usg=AFQjCNEIr RvMO5bgyoY510FXJHoZ62_3jQ\&bvm=bv.53217764,d.aWM (accessed on 30 August 2013).

34. Cohendet, P.; Grandadam, D.; Simon, L. Rethinking urban creativity: Lessons from Barcelona and Montreal. City Culture Soc. 2011, 2, 151-158.

35. Micelli, E. La Gestione Dei Piani Urbanistici. Perequazione, Accordi, Incentivi (in Italian); Marsilio: Venezia, Italy, 2011.

36. International Council in Monuments and Sites (ICOMOS). Guidance on Heritage Impact Assessments for Cultural World Heritage Properties; ICOMOS: Paris, France, 2010.

37. Pereira Roders, A.; van Oers, R. Guidance on heritage impact assessments. J. Cult. Herit. Manag. Sustain. Dev. 2012, 2, 104-114

38. Nijkamp, P. Economic Valuation of Cultural Heritage. In The Economics of Uniqueness; Licciardi, G., Amirtahmasebi, R., Eds.; World Bank: Washington, DC, USA, 2012.

39. Cerreta, M.; de Toro, P. Assessing urban transformations: A SDSS for the master plan of Castel Capuano, Naples. Lect. Notes Comput. Sci. 2012, 7334, 168-180.

40. Cerreta, M.; Mele, R. A landscape complex value map: Integration among soft values and hard values in a spatial decision support. Lect. Notes Comput. Sci. 2012, 7334, 653-659.

41. Cerreta, M.; Panaro, S.; Cannatella, D. Multidimensional spatial decision-making process: Local shared values in action. Lect. Notes Comput. Sci. 2012, 7334, 54-70.

42. Cerreta, M.; de Toro, P. Integrated spatial assessment for a creative decision-making process: A combined methodological approach to strategic environmental assessment. Int. J. Sustain. Dev. 2010, 13, 17-30.

43. Fusco Girard, L.; de Toro, P. Integrated spatial assessment: A multicriteria approach to sustainable development of cultural and environmental heritage in San Marco dei Cavoti, Italy. Cent. Eur. J. Oper. Res. 2007, 15, 281-299.

44. Fusco Girard, L.; Torre, C.M. The use of Ahp in a multiactor evaluation for urban development programs: A case study. Lect. Notes Comput. Sci. 2012, 7334, 157-167. 
45. Fusco Girard, L.; Nijkamp, P. Le Valutazioni Per Lo Sviluppo Sostenibile Della Città e Del Territorio (in Italian); FrancoAngeli: Milano, Italy, 1997.

46. KEA European Affairs. Measuring economic impact of CCIs policies-How to justify investment in cultural and creative assets. European Union: Brussels, Belgium, 2012.

47. Zeleny, M. Human System Management; SOS: Amsterdam, The Netherlands, 2005.

48. Ravetz, J. Exploring Creative Cities for Sustainability with Deliberative Visualization. In Sustainable City and Creativity. Promoting Creative Urban Initiatives; Fusco Girard, L., Baycan, T., Nijkamp, P., Eds.; Ashgate: Aldershot, UK, 2011.

(C) 2013 by the authors; licensee MDPI, Basel, Switzerland. This article is an open access article distributed under the terms and conditions of the Creative Commons Attribution license (http://creativecommons.org/licenses/by/3.0/). 